- lack of staff to assist in contacting the exposed mothers by phone over the four-day Christmas holiday period;

- inadequate, incorrect, or out-of-date contact information for many mothers;

- overload of the Emergency Department with anxious parents during a busy holiday period;

- exhaustion of the hospital's stock of erythromycin and difficulty obtaining extra stock over the holiday period.

To avoid such problems in future, the Western Sydney Area Public Health Unit has developed a protocol for dealing with outbreaks of infectious disease. This protocol emphasises early recognition of the potential for large numbers of contacts, and identification of alternative options for implementing public health interventions, such as providing special facilities within the outpatients department or at community health centres.

\section{REFERENCES}

1. NSW Health Department. NSW Public Health Bulletin 1997; 8:8-9 (August-September, 1997), 73.

2. AIDS/Infectious Diseases Branch, NSW Health Department. Infectious Diseases Manual, 5th edn, Sydney: NSW Health Department, 1995.

\title{
PERTUSSIS: A COMMENT
}

\section{Peter B. McIntyre}

\section{Deputy Director}

National Centre for Immunisation Research and Surveillance of Vaccine Preventable Diseases New Children's Hospital, Westmead

The article by Vella et al. highlights the practical difficulties of managing exposure to pertussis in the health care setting. It is likely that other instances of exposure of newborn infants to pertussis in the health care setting have occurred in New South Wales during the period of highest pertussis activity in 1996-97. The method of diagnosis of the index case is not stated-a positive culture would have been of greater concern than positive serology alone. No data were presented describing compliance with the recommended course of erythromycin. Few of those who obtained erythromycin are likely to have completed a full 10-day course for themselves or their infants. However, erythromycin prophylaxis has been shown to be effective in the more intense exposure situation of mother to infant, ${ }^{1}$ and appears to have been effective in the present hospital outbreak. As pointed out by the authors, this incident prompted a public health response and raises at least two questions. Is the transmission of pertussis to patients (including but not limited to neonates) by health care workers a significant problem? What role is there for pertussis boosters for health care workers or adults in general?

The first report to draw attention to the then barely recognised problem of adult pertussis was from Sydney in $1978 .^{2}$ Australia currently has one of the highest notification rates for pertussis in persons over 20 years of age among countries with established pertussis immunisation programs. ${ }^{3}$ Adults are estimated to have been responsible for introducing infection into the household in approximately 15 per cent of cases. ${ }^{4}$ Although whole cell pertussis vaccine has been used successfully to terminate outbreaks in an institutional setting, it has generally been considered unsuitable for use in adults. ${ }^{5}$ Current infant/child acellular pertussis vaccines must also be modified for use in adults by reducing the amount of pertussis antigens as well as the diphtheria and tetanus content.

A trial of such a vaccine in 550 adults was recently carried out by the Centre for Immunisation Research at the New 
Children's Hospital, with a preliminary report at the recent National Immunisation Conference in Melbourne. ${ }^{6}$ The vaccine was well tolerated, with good immune responses; efficacy was not examined. A randomised controlled trial of acellular pertussis vaccine in adults, with endpoints of clinical or serologic pertussis, is currently under way in the United States. The evidence from these and other trials on efficacy and tolerability will provide a good basis for decisions on the use of pertussis vaccines in adolescents and adults.

Given the difficulty of immunising adults at a community level, implementation of additional pertussis boosters after the age of five years is most likely to be feasible as part of a secondary school-based program. However, health care workers are an identifiable and accessible target group for immunisation. A review of management of patients and health care workers exposed to pertussis recommends wearing of a mask until five days of erythromycin prophylaxis have been completed or restriction from work if pertussis develops. ${ }^{7}$ This is clearly a big ask! Health care workers generally have levels of antibody to pertussis antigens that are no higher than those in the general population, so they would be expected to be no less susceptible to infection. ${ }^{8}$ The expense and potentially high morbidity associated with pertussis exposure in hospitals, particularly with those exposed to infants, will make use of acellular pertussis vaccine in at least some subgroups of health care workers an attractive option in the hospital environment. ${ }^{9}$

\section{REFERENCES}

1. Granstrom G, Sterner G, Nord CE, et al. Use of erythromycin to prevent pertussis in newborns of mothers with pertussis. $J$ Infect Dis 1987; 155: 1210-1214.

2. Robertson PW, Goldberg H, Jarvie BH, et al. Bordetella pertussis infection: a cause of persistent cough in adults. Med J Aust 1987; 146: 522-525.

3. Andrews R, Herceg A, Roberts C. Pertussis notifications in Australia, 1991 to 1997. Commun Dis Intell 1997; 21: 145148.

4. Keitel WA, Edwards KM. Pertussis in adolescents and adults: time to reimmunise? Sem in Resp Infections 1995; 10: 51-57.

5. Leinnemann CC, Ramundo N, Minton SD, et al. Use of pertussis vaccine in an epidemic involving hospital staff. Lancet 1975; ii: 540-543.

6. Turnbull F, Heath T, Jalaludin B, et al. A single blinded randomised trial comparing two adult acellular pertussis vaccines with licensed adult diphtheria - tetanus vaccine (ADT). Proceedings of the 6th National Public Health Immunisation Conference: Immunisation beyond 2000. Public Health Association of Australia: Canberra, November 1999; 24.

7. Haiduven DJ, Hench CP, Simpkins SM, et al. Standardised management of patients and employees exposed to pertussis. Infect Control Hosp Epidemiol 1998; 19: 861-864.

8. Wright SW, Edwards KM, Decker MD, et al. Pertussis seroprevalence in emergency department staff. Ann Emerg Med 1994; 24: 413-417.

9. Christie CD, Glover AM, Wilkie MJ, et al. Infect Control Hosp Epidemiol 1995; 16: 556-563.

\section{CHANGES TO THE BULLETIN'SWEB SITE}

We are pleased to announce the following changes to the Bulletin's Web site:

- Cumulative subject and author indexes for the period 1990-1998 are now available in an HTML format. These indexes are located at the beginning of the Web site and will be updated annually.

- All issues of the Bulletin since it was first published in May 1990 are now available from the Web site. They have been scanned as PDF files and are available in an Acrobat format. An Acrobat reader is freely provided from the Web site.

The electronic version of each new Bulletin is usually accessible from the Web site before the hardcopy version is printed and distributed. We encourage you to bookmark our Web site and visit us there often at http://www.health.nsw.gov.au/public-health/phb/phb.html. 